\title{
A laboratory design for uniaxial hot pressing
}

\author{
D S MUNGEKAR*, K B BHATT and A J SINGH \\ Chemistry Division, Bhabha Atomic Research Centre, Trombay, Bombay 400085 , India \\ MS received 12 March 1990; revised 1 August 1990
}

\begin{abstract}
A design to hot press uniaxially compacts of $12 \mathrm{~mm}$ diameter and $15 \mathrm{~mm}$ long and its assembly has been described. The hot press was successfully employed to demonstrate conversion of $\mathrm{BN}$ powder into hexagonal machinable variety at $1800^{\circ} \mathrm{C}$ and 80 bars pressure.
\end{abstract}

Keywords. Uniaxial hot pressing; hot densification; machinable BN.

\section{Introduction}

Hot pressing (Moore 1977) is a material processing technique which, besides imparting high densities, yields compacts having controlled microstructure, greater strength and improved properties. Several materials undergo structural transformations when subjected to hot pressing and these transformations may result in materials with superior properties. In hot pressing, pressure and heat are applied simultaneously. The mode of application of the heat to the compact may be direct (through resistance or induction heating) or indirect (through convection or conduction). The application of pressure to the heated sample can be by hot isostatic pressing (HIP) or uniaxial hot pressing (UHP). HIP has limitations primarily due to difficulties associated with hermetical sealing and the non-availability of suitable deformable container materials at high temperatures. Such difficulties at high temperatures $\left(>1800^{\circ} \mathrm{C}\right)$ are by and large circumvented in UHP by the use of pressure components machined from graphite, which is a unique material with respect to its high strength at elevated temperatures, easy machinability and fairly good electrical conductivity. The latter property renders it specially suitable for resonance frequency $(R F)$ and resistance heating.

In the present report, an indigenously fabricated uniaxial hot pressing system for laboratory use is described which is workable up to $1850^{\circ} \mathrm{C}$ and at a maximum pressure of 100 bars. Special features incorporated in the system are the capability to perform uniaxial hot pressing in the desired ambient or in vacuo.

\section{System description}

Figure 1 shows the schematic of the uniaxial hot pressing system designed and fabricated in our workshop. In this system, the material of compact, graphite die and punches, spacers and the thermal insulation are all placed inside a clear quartz tube of $40 \mathrm{~mm}$ OD, $2 \mathrm{~mm}$ wall thickness and $180 \mathrm{~mm}$ length, which also constitutes the chamber whose ambient can be controlled. An RF work coil, of $45 \mathrm{~mm}$ ID and $60 \mathrm{~mm}$ height, made out of $4.5 \mathrm{~mm}$ ID copper tubing, is positioned outside the quartz chamber so that the gap between coil and quartz tube is $2.5 \mathrm{~mm}$, to impart induction heating to

*For correspondence 


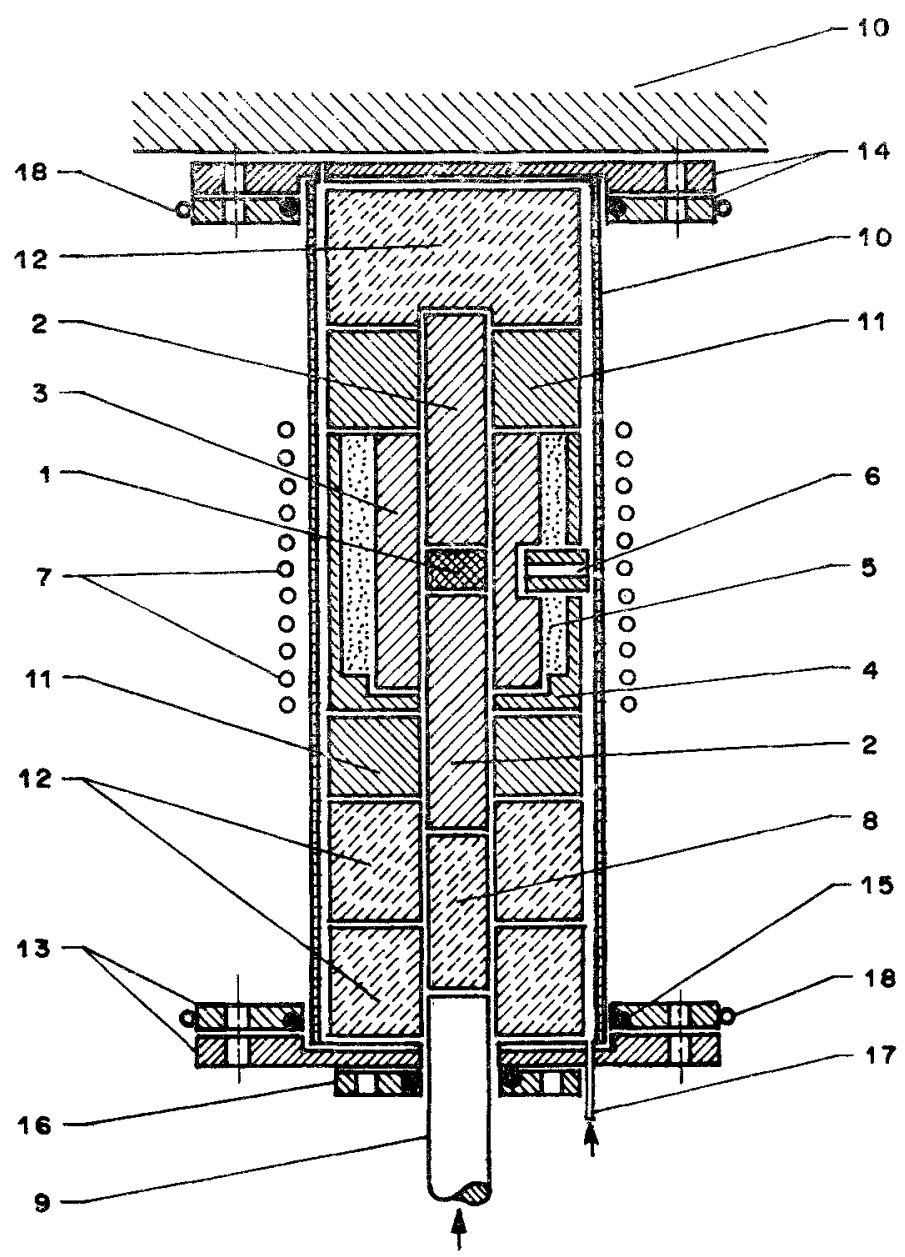

Figure 1. Uniaxial hot pressing assembly (schematic). (1) Sample, (2) graphite punches, (3) graphite die, (4) BN housing, (5) graphite powder insulation, (6) BN tube for viewing, (7) RF coil, (8) pyrophylite punch, (9) SS plunger of hydraulic press, (10) transparent quartz tube, (11) BN spacers, (12) pyrophilite spacers, (13) lower SS flange, (14) upper SS flange, (15) 'O' ring seals, (16) sealed flange of SS plunger, (17) gas/vacuum connection, (18) copper tubing for water circulation, and (19) MS stand as stopper.

the graphite components. Both ends of the quartz tube are provided with SS flanges having an ' $O$ ' ring sealing and arrangement for water cooling. Unidirectional pressure is transmitted through the hydraulic pump and a train of space punches from the bottom. The lower flange has an opening for gas passage or alternatively for evacuating the quartz chamber. The upper flange cover rests against a rugged mild steel stand which acts also as stopper for the uppermost spacer made out of pyrophylite with subsequent baking at $700^{\circ} \mathrm{C}$. This flange cover is provided with an orifice for the gas outlet when the hot pressing is intended in gas ambient. Alternatively, when evacuation of the chamber is sought, an identical flange cover without an orifice is employed. The graphite die having $12.5 \mathrm{~mm}$ ID, $25 \mathrm{~mm}$ OD and $34 \mathrm{~mm}$ height and punches of $12.5 \mathrm{~mm}$ dia and $30 \mathrm{~mm}$ height are accommodated inside a cup-shaped housing which was 


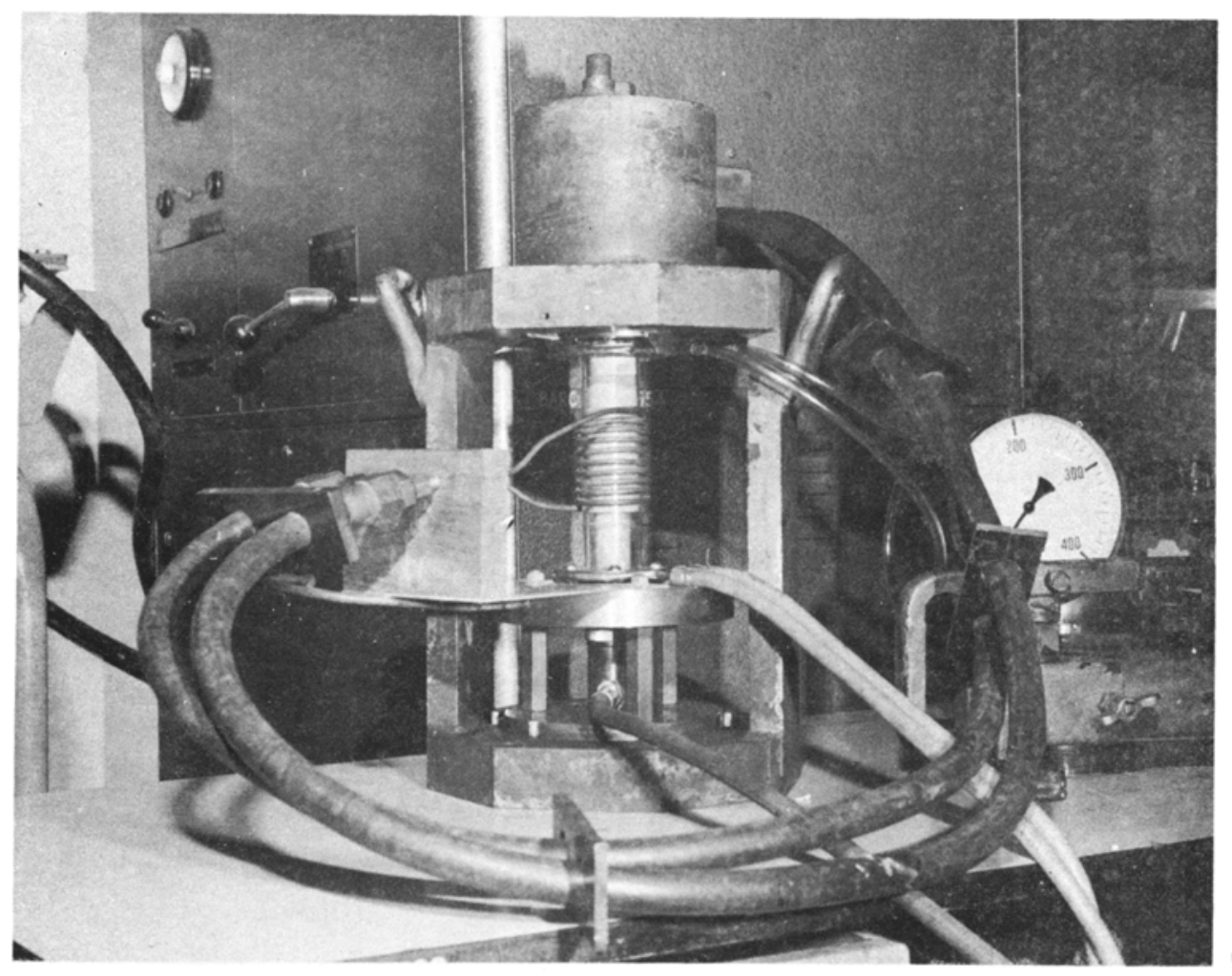

(a)

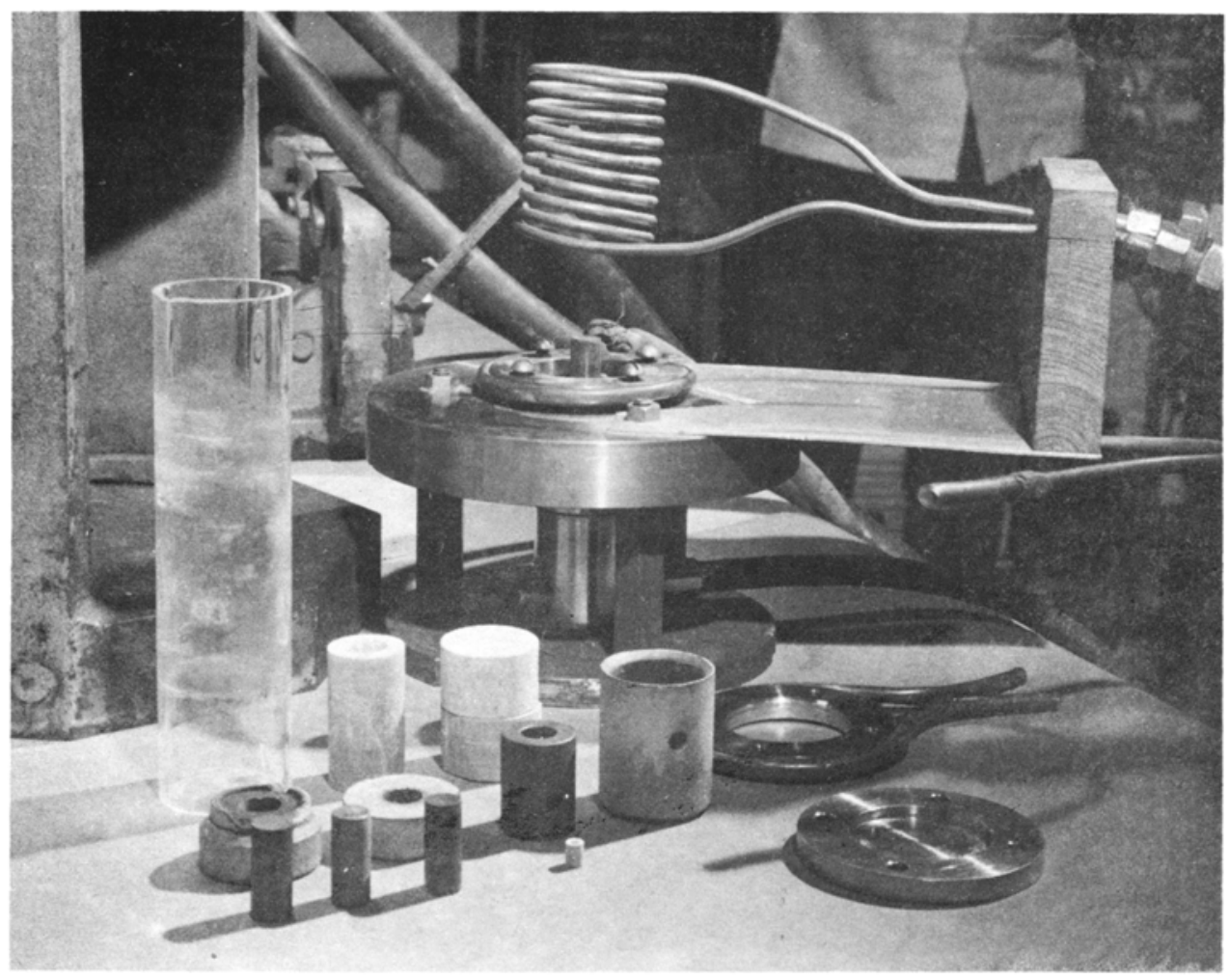

(b)

Figure 2. Photographs of uniaxial hot-pressing assembly. 
machined out of boron nitride (BN). The space between the graphite die and the inner wall of the BN housing is packed with high purity graphite powder $199.999 \%$ pure, grade U50-4S, Ultra Carbon, USA) which serves as an excellent thermal insulator. Measurement of the working temperature on the graphite die is effected pyrometrically through a viewing window of $3 \mathrm{~mm} \mathrm{ID}, 6 \mathrm{~mm} O \mathrm{D}$ and $8 \mathrm{~mm}$ length also fabricated out of machinable BN. The stress, as indicated from ligure 1 is applied perpendicular to the axis of the load train and unidirectionally from the lower graphite die. During operation, the hydraulic pressure is kept constant by manual manipulation of hydraulic pump. Figure 2 shows photographs of the hot pressing assembly, hydraulic pump and RF induction coil.

\section{Results and discussion}

The use of graphite is limited because of the need to provide a protective environment and the maximum temperature of $2500^{\circ} \mathrm{C}$ employable without apparent evaporation in vacuum. Machining of the graphite die and punches was done accurately to ensure that components do not fracture under bursting stresses on compacting and thermal stresses due to rapid heating and cooling. Induction heating with an outer work coil was considered workable because the graphite susceptor can reach temperature up to $2000^{\circ} \mathrm{C}$. Graphite powder, which did not couple with the RF (1 MHz, $10 \mathrm{~kW}$ output) served as an excellent thermal insulator. Other design features of the assembly were (i) to ensure that an inert ambient exists for graphite, and (ii) retention of graphite powder in a passive as well as non-susceptor container made out of machinable BN.

The measurement of temperature inside the chamber did not pose any particular problem because of the clear quartz tube through which the pyrometric readings were conveniently made.

The demonstration of uniaxial hot pressing assembly was done by conducting a few experiments on $\mathrm{BN}$ powder prepared in the laboratory (Khan et al 1979), in which temperature was varied between 1350 and $1850 \mathrm{C}$ and pressure between 60 and 100 bars. Up to $94 \%$ of the theoretical density (Taylor 1955 ) of BN was obtained. In a typical hot-pressing run $\mathrm{BN}$ pellets (containing $1 \% \mathrm{~B}_{2} \mathrm{O}$ by weight as binder and cold-pressed at 100 bars) of $12 \mathrm{~mm}$ diameter and $18 \mathrm{~mm}$ length. were placed between the two graphite punches and the whole train of punches was then assembled ensuring that insulating spacers and punches were placed both above and below the graphite punches in order to circumvent RF pick-ap by the mild steel and other components of the assembly. Prior to heating and pressutising, nitrogen gas (IOLAR II grade) was continuously passed through the quartz chamber to provide an inert ambient for the graphite ware. Pressure was applied hydrostatically from the bottom punch by manually operating the pump. As heating of the graphite die progressed, the hydrostatic pressure was manually kept steady with the pump. The contraction of the BN sample on account of compacting was evinced by a drop in the pressure which was eventually increased to 80 bars by pumping. Altainment of $1850 \pm 15^{\circ} \mathrm{C}$ was determined pyrometrically. After hot pressing for about 10 minutes no further drop in the pressure was observed. indicating maximum densification of the compact under these experimental conditions.

Typically, the density of the hot pressed $B$ was increased from $1.33 \mathrm{~g} / \mathrm{cm}^{3}$ to $2.11 \mathrm{~g} / \mathrm{cm}^{3}$ showing achievement of $94 \%$ of the theoretical density $\left(2.25 \mathrm{~g} / \mathrm{cm}^{3}\right)$. The 


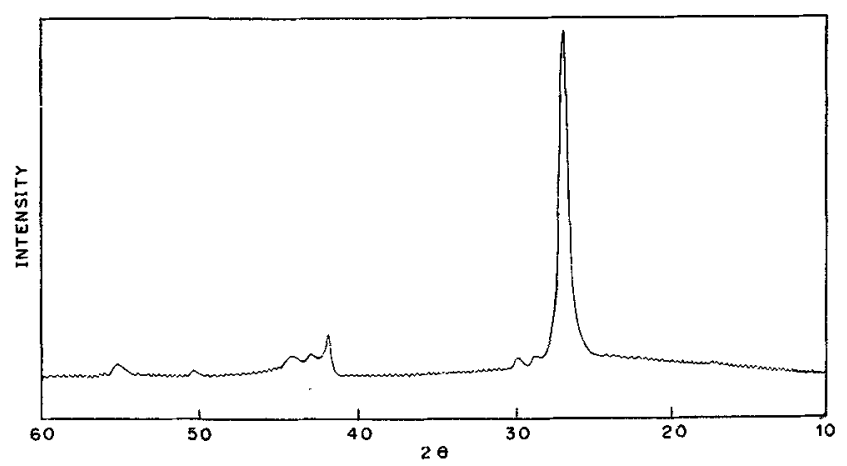

Figure 3. X-ray diffraction spectrum of starting $\mathrm{BN}$ material.

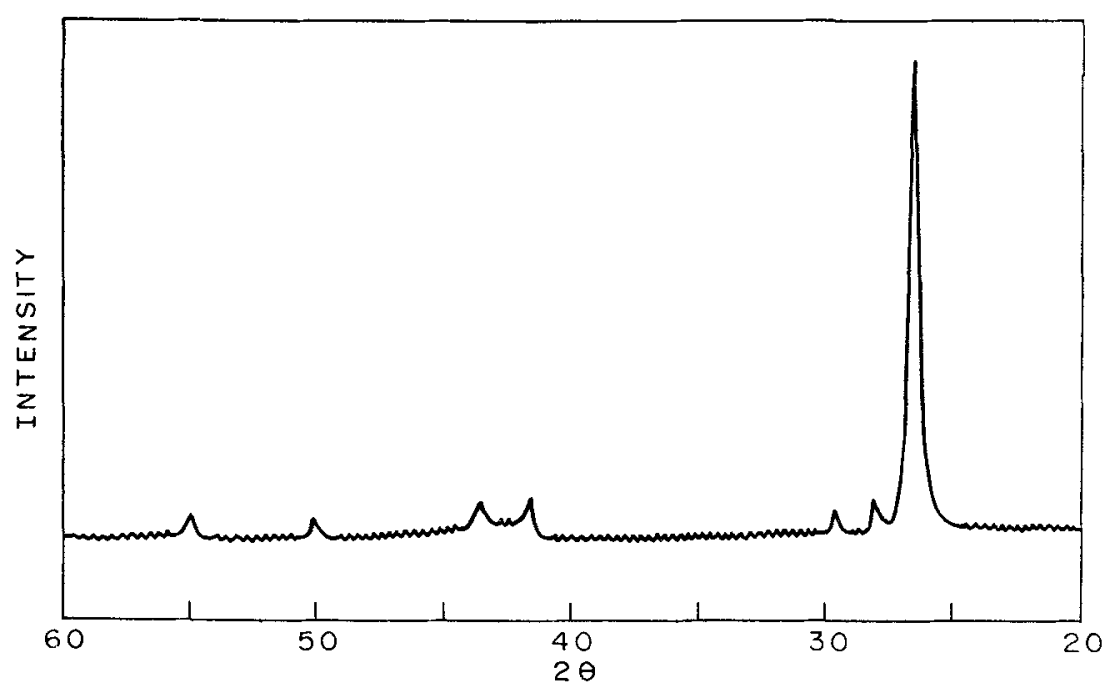

Figure 4. X-ray diffraction spectrum of hot-pressed BN material.

change of the turbostratic variety (O'Connor 1962) of $\mathrm{BN}$ into the ordered-layer hexagonal variety was confirmed by comparing the $\mathrm{X}$-ray powder diffraction spectra of both the pre- and post-hot pressed BN. The hot-pressed BN showed appreciable narrowing of the full width at half maximum (FWHM). The peaks observed at $2 \theta=26.77^{\circ}$ (100 intensity), figures 3 and 4 , have FWHM values of 0.65 and $0.35^{\circ}$ respectively for the starting sample and the hot-pressed $B N$.

The hexagonal variety of BN obtained by the uniaxial hot pressing was machinable and could be made into small crucibles.

\section{References}

Khan I A, Ahuja H S and Rao G S 1979 Bhabha Atomic Research Centre Rep. No. I-156

Moore A W 1977 High pressure technology (eds) I L Spain and J Paauwe (New York: Marcel Dekker) vol 2, chap. 11, p. 409

O'Connor T E $1962 \mathrm{~J}$. Am. Chem. Soc. 841753

Taylor K M 1955 Ind. Eng. Chem. 472506 